\title{
OPEN Enhancement of tumor tropism of mPEGylated nanoparticles by anti-mPEG bispecific antibody for ovarian cancer therapy
}

Wen-Wei Lin ${ }^{1,2,3,4,13,14}$, Yi-An Cheng ${ }^{3,5,14}$, Chia-Ching $\mathrm{Li}^{3,5}$, Kai-Wen $\mathrm{Ho}^{2}$, Huei-Jen Chen ${ }^{2}$, I.-J.u Chen ${ }^{3,5}$, Bo-Cheng Huang ${ }^{6}$, Hui-Ju Liu' ${ }^{2}$, Yun-Chi Lu ${ }^{3,5}$, Chiu-Min Cheng ${ }^{7}$, Ming-Yii Huang ${ }^{8}$, Hung-Wen Lai ${ }^{9,10,11,12 \bowtie ~ \& ~ T i a n-L u ~ C h e n g ~}{ }^{2,3,4,5 \bowtie}$

Ovarian cancer is highly metastatic, with a high frequency of relapse, and is the most fatal gynecologic malignancy in women worldwide. It is important to elevate the drug susceptibility and cytotoxicity of ovarian cancer cells, thereby eliminating resident cancer cells for more effective therapeutic efficacy. Here, we developed a bispecific antibody (BsAb; mPEG $\times$ HER2) that can easily provide HER2 ${ }^{+}$tumor tropism to $\mathrm{mPEGylated} \mathrm{liposomal} \mathrm{doxorubicin} \mathrm{(PLD)} \mathrm{and} \mathrm{further} \mathrm{increase} \mathrm{the} \mathrm{drug} \mathrm{accumulation}$ in cancer cells via receptor-mediated endocytosis, and improve the cytotoxicity and therapeutic efficacy of HER2 ${ }^{+}$ovarian tumors. The MPEG $\times$HER2 can simultaneously bind to mPEG molecules on the surface of PLD and HER2 antigen on the surface of ovarian cancer cells. Simply mixing the mPEG $\times$ HER2 with PLD was able to confer HER2 specificity of PLD to HER2 ${ }^{+}$ovarian cancer cells and efficiently trigger endocytosis and enhance cytotoxicity by 5.4 -fold as compared to non-targeted PLD. mPEG $\times$ HER2-modified PLD was able to significantly increase the targeting and accumulation of HER2 ${ }^{+}$ovarian tumor by $220 \%$ as compared with non-targeted PLD. It could also significantly improve the anti-tumor activity of PLD $(P<0.05)$ with minimal obvious toxicity in a tumor-bearing mouse model. We believe that the mPEG $\times$ HER2 can significantly improve the therapeutic efficacy, potentially reduce the relapse freqency and thereby achieve good prognosis in ovarian cancer patients.

Ovarian cancer ranks as the seventh most common cancer worldwide and the most fatal gynecologic cancer in women with over 22,000 new cases and 14,000 disease-related deaths each year in the United State ${ }^{1}$. These data suggest that almost $55 \%$ of all ovarian cancer patients will eventually die from the disease ${ }^{1}$. The high mortality rate of ovarian cancer can be partly ascribed to the majority of patients (approximately 75\%) presenting with high-grade disease ${ }^{2,3}$ usually accompanied with metastatic disease in the peritoneal cavity ${ }^{2}$. Although patients can receipt intraperitoneal (IP) chemotherapy (e.g. injected paclitaxel, cisplatin or carboplatin through a catheter) after tumor were optimally debulked and it seems to help some patient live longer than intravenous (IV)

${ }^{1}$ Department of Laboratory Medicine, School of Medicine, College of Medicine, Kaohsiung Medical University, Kaohsiung, Taiwan. ${ }^{2}$ Graduate Institute of Medicine, College of Medicine, Kaohsiung Medical University, Kaohsiung, Taiwan. ${ }^{3}$ Drug Development and Value Creation Research Center, Kaohsiung Medical University, Kaohsiung, Taiwan. ${ }^{4}$ Department of Medical Research, Kaohsiung Medical University Hospital, Kaohsiung, Taiwan. ${ }^{5}$ Department of Biomedical Science and Environmental Biology, Kaohsiung Medical University, 100 Shih-Chuan 1st Road, Kaohsiung 80708, Taiwan. ${ }^{6}$ Institute of Biomedical Sciences, National Sun Yat-Sen University, Kaohsiung, Taiwan. ${ }^{7}$ Department of Aquaculture, National Kaohsiung University of Science and Technology, Kaohsiung, Taiwan. ${ }^{8}$ Department of Radiation Oncology, Cancer Center, Kaohsiung Medical University Hospital, Kaohsiung, Taiwan. ${ }^{9}$ Endoscopic and Oncoplastic Breast Surgery Center, Comprehensive Breast Cancer Center, Changhua Christian Hospital, 135 Nanxiao Street, Changhua 500, Taiwan. ${ }^{10}$ Division of General Surgery, Changhua Christian Hospital, Changhua, Taiwan. ${ }^{11}$ Comprehensive Breast Cancer Center, Changhua Christian Hospital, Changhua, Taiwan. ${ }^{12}$ Minimal Invasive Surgery Research Center, Changhua Christian Hospital, Changhua, Taiwan. ${ }^{13}$ Department of Laboratory Medicine, Post Baccalaureat Medicine, College of Medicine, Kaohsiung Medical University, Kaohsiung, Taiwan. ${ }^{14}$ These authors contributed equally: Wen-Wei Lin and Yi-An Cheng. email: 143809@cch.org.tw; tlcheng@kmu.edu.tw 
chemotherapy alone, however, patients may suffer more severe side effect such as abdominal pain, nausea or vomiting during treatment ${ }^{1}$. Development of a more effective therapeutic strategy for enhancing the therapeutic efficacy of primary or even metastatic ovarian cancer is urgently needed. Methoxyl-polyethylene glycol (mPEG)-labeled liposomal doxorubicin (mPEGylated LD; PLD) is a liposomal nanomedicine that is approved by US Food and Drug Administration (FDA) for clinical use $e^{4-7}$. It is most frequently (90.7\% of cases) used as a single chemotherapeutic agent or combinatory therapeutic option for the non-platinum treatment of ovarian cancer patients ${ }^{8-11}$. However, lack of targeted and endocytic ability of PLD to cancer cells and the passive diffused cytotoxic mechanism of PLD may make it hard to eliminate all resident cancer cells after primary debulking surgery, thereby elevating the relapse frequency of ovarian cancer ${ }^{12}$ or even inducing severe adverse events that decrease quality of life of ovarian cancer patients during treatment ${ }^{13}$. For example, Gordon et al. suggest that PLD treatment not only failed to prolong the overall survival (OS) rate of platinum-resistant ovarian cancer patients as compared with topotecan treatment but also induced serious adverse events including palmar-plantar erythrodysesthesia (PPE), stomatitis, and mucositis ${ }^{13-15}$. It is important to improve the targeting ability and endocytic efficiency of PLD to target cells for more effective therapeutic efficacy of ovarian cancer.

In this study, we developed a humanized bispecific antibody (BsAb; mPEG $\times$ HER2) to easily confer ovarian tumor tropism to PLD. The BsAb consists of one arm of Fab fragment against mPEG, which is lipid anchored on the surface of PLD ${ }^{5,16-18}$, and the other arm of single chain $\mathrm{Fv}(\mathrm{scFv})$ fragment against human epidermal growth factor receptor 2 (HER2) antigen, which is overexpressed on approximately $50 \%$ of ovarian cancer cells ${ }^{19-21}$. Simply mixing $\mathrm{mPEG} \times$ HER2 with PLD can easily provide tumor specificity and lead PLD to actively target HER2-overexpressed ovarian tumors and further trigger receptor-mediated endocytosis, thereby enhancing cytotoxicity and therapeutic efficacy in ovarian cancer (Supplementary Figure S1). We first analyzed the functions of both arms of $\mathrm{mPEG} \times$ HER2 and the HER 2 specificity of $\mathrm{mPEG} \times$ HER2-modified PLD by antigen-based ELISA or cell-based ELISA, respectively. The endocytic ability and efficiency of mPEG $\times$ HER2-modified PLD was examined by flow cytometry and confocal live cell imaging. The cytotoxicity of HER2-targeted PLD was further measured by cell viability assay. The tumor accumulation and therapeutic efficacy of mPEG $\times$ HER2modified PLD were finally evaluated in the HER2 ${ }^{+}$ovarian tumor-bearing mouse model. We believe that the increased cytotoxicity of targeted PLD can reduce the opportunity of residual ovarian cancer cell survival from conventional PLD treatment and improve the prognosis of ovarian cancer patients.

\section{Materials and methods}

Cells and animals. SKOV-3 human ovary adenocarcinoma cells (American Type Culture Collection, Manassas, VA, USA) were cultured in Dulbecco's modified Eagle's medium (DMEM; Sigma-Aldrich, St Louis, MO, USA) containing 10\% (v/v) fetal bovine serum (FBS; Biological industries, Cromwell, CT, USA) and 100 units $\mathrm{mL}^{-1}$ penicillin and streptomycin (Invitrogen, Calsbad, CA, USA), at $37^{\circ} \mathrm{C}$ in a humidified atmosphere of $5 \%(\mathrm{v} / \mathrm{v}) \mathrm{CO}_{2}$. MDA-MB-468 mammary adenocarcinoma cells (American Type Culture Collection, Manassas, VA, USA) were cultured in DMEM containing $10 \%(\mathrm{v} / \mathrm{v})$ bovine calf serum (BCS; Thermo, Waltham, MA, USA) and 100 units $\mathrm{mL}^{-1}$ penicillin and streptomycin, at $37^{\circ} \mathrm{C}$ in a humidified atmosphere of $5 \%(\mathrm{v} / \mathrm{v}) \mathrm{CO}_{2}^{22}$. Expi293F cells (Thermo, Waltham, MA, U.S.A.) were cultured in Expi293 expression medium (Thermo, Waltham, MA, USA) on shakers ( $25 \mathrm{~mm}$ shaking diameter) with a shake speed of $120 \mathrm{rpm}$ in a humidified atmosphere of $8 \%$ $\mathrm{CO}_{2}$ in air at $37^{\circ} \mathrm{C}^{22}$. Specific pathogen-free 6- to 8-week-old female BALB/c nude mice (BALB/cAnN.CgFoxn1nu/CrlNarl) were purchased from the National Laboratory Animal Center, Taipei, Taiwan. All animal procedures were performed in accordance with the Guidelines for Care and Use of Laboratory Animals and approved by the Institutional Animal Care and Use Committee (IACUC) of Kaohsiung Medical University.

Antibodies and reagents. Hybridomas secreting 6.3 (IgG1 mAbs against PEG) have been described ${ }^{17}$. Monoclonal antibodies were purified from the ascites fluid of mice by affinity chromatography on Protein G Sepharose (GE Healthcare, Little Chalfont, UK) in high-salt buffer. Horseradish peroxidase (HRP)-conjugated goat anti-mouse IgG Fc antibody, HRP-conjugated goat anti-human Fab antibody, HRP-conjugated goat antirabbit IgG $(\mathrm{H}+\mathrm{L})$ antibody and fluorescein isothiocyanate (FITC)-conjugated goat anti-mouse IgG antibody were from Jackson ImmunoResearch Laboratories (Westgrove, PA, USA). Methoxyl PEGylated-liposomal doxorubicin (PLD; Lipo-Dox) was from Taiwan Tung Yang Biopharm (TTY Biopharm Company, Taipei, Taiwan). Lipo-DiR and Lipo-DiD (PEGylated DOPC/CHOL liposomes labeled with DiR) were purchased from FormuMax Scientific (Sunnyvale, CA, USA).

Plasmid construction, expression and purification. The construction of mPEG $\times$ HER 2 and $\mathrm{mPEG} \times \mathrm{DNS}$ was as described in a previous study ${ }^{23}$. In brief, $\mathrm{mPEG} \times \mathrm{HER} 2$ was generated by fusion of the $\mathrm{C}$ terminus of an anti-mPEG Fab (clone h15-2b) ${ }^{17}$ with an anti-HER2 ${ }^{23}$ or anti-DNS scFv ${ }^{24}$ through a flexible peptide linker (GGGGS) ${ }_{3}$ and $\mathrm{mPEG} \times \mathrm{HER} 2$ and $\mathrm{mPEG} \times \mathrm{DNS}$ were formed, respectively. The $\mathrm{V}_{\mathrm{L}}-\mathrm{C}_{\mathrm{K}}$ and $\mathrm{V}_{\mathrm{H}}-\mathrm{C}_{\mathrm{H}_{1}}{ }^{-}$ linker-scFv fragments of $\mathrm{mPEG} \times \mathrm{HER} 2$ or $\mathrm{mPEG} \times \mathrm{DNS}$ were separated with an IRES in the pLNCX retroviral vector (BD Biosciences, San Diego, CA, USA) to generate pLNCX-mPEG $\times$ HER2 and pLNCX-mPEG $\times$ DNS plasmids, respectively. Expi293 cells were transfected with plasmids and the culture medium was collected after 5 days. The BsAbs were purified by affinity chromatography on methoxyl-PEG ${ }_{750}\left(\mathrm{mPEG}_{750}\right)$-coated CNBr-activated sepharose 4B (GE Healthcare, Little Chalfont, UK) $)^{23}$.

Enzyme-linked immunosorbent assay (ELISA). The binding function of anti-mPEG Fab and antiHER2 scFv arm in $\mathrm{mPEG} \times$ HER2 was separately analyzed by $m$ PEGylated protein-based ELISA or HER2 ${ }^{+}$cellbased ELISA, respectively. To evaluate the binding ability of anti-mPEG Fab arm, maxisorp 96-well microplates (Nalge Nunc International, Roskilde, Denmark) were coated with $20 \mu \mathrm{g} \mathrm{mL} \mathrm{m}^{-1}$ of $\mathrm{mPEG}_{2 \mathrm{~K}}$-labeled bovine serum 
albumin (BSA) in $50 \mu \mathrm{L}$ well ${ }^{-1}$ of $0.1 \mathrm{M} \mathrm{NaHCO}_{3}\left(\mathrm{pH} 9.0\right.$ ) at $37{ }^{\circ} \mathrm{C}$ for $2 \mathrm{~h}$ and then blocked with $200 \mu \mathrm{L}$ well $^{-1}$ of dilution buffer [ $5 \%$ (wt/vol) skim milk in PBS] overnight at $4{ }^{\circ} \mathrm{C}$. Serial dilutions of $\mathrm{mPEG} \times \mathrm{HER} 2$ or $\mathrm{mPEG} \times \mathrm{DNS}$ were added to the wells at room temperature (RT) for $45 \mathrm{~min}$. After extensive washing, the bound BsAb was detected by HRP-conjugated anti-human Fab secondary Ab. The plates were washed with PBS, and bound peroxidase activity was measured by adding $150 \mu \mathrm{L}$ well ${ }^{-1}$ of ABTS solution $\left[0.4 \mathrm{mg} \mathrm{mL}^{-1}, 2^{\prime}\right.$-azinobis (3-ethylbenzthiazoline-6-sulfonic acid), $0.003 \%$ (v/v) $\mathrm{H}_{2} \mathrm{O}_{2}$, and $100 \mathrm{mM}$ phosphate-citrate, $\mathrm{pH} 4.0$ ] for $40 \mathrm{~min}$ at RT. Color development was measured at $405 \mathrm{~nm}$ on a EZ Read 400 ELISA (Biochrom). The binding ability of the anti-HER2 $\mathrm{scFv}$ arm in $\mathrm{mPEG} \times$ HER 2 was examined by HER2 ${ }^{+}$cell-based ELISA. HER2 ${ }^{+}$SKOV-3 cells $\left(2 \times 10^{5}\right)$ were seeded in poly-D-lysine $\left(50 \mu \mathrm{g} \mathrm{mL} \mathrm{m}^{-1}\right.$, Corning, New York, USA)-coated 96-well cell culture plates overnight at $37^{\circ} \mathrm{C}$. After washing, the cells were fixed with $2 \%(\mathrm{w} / \mathrm{v})$ paraformaldehyde for $5 \mathrm{~min}$ at RT and the reaction was stopped by the neutralization of $0.1 \mathrm{M}$ glycine solution at RT for $2 \mathrm{~h}$. Serial dilutions of $\mathrm{mPEG} \times$ HER 2 or $\mathrm{mPEG} \times \mathrm{DNS}$ were added to each well and reacted at RT for $45 \mathrm{~min}$. After extensive washing with PBS, $10 \mu \mathrm{g} \mathrm{mL}^{-1}$ of $\mathrm{mPEG}_{2 \mathrm{~K}}-\mathrm{BSA}$ was added to the wells for $20 \mathrm{~min}$. After washing, the bound $\mathrm{mPEG}_{2 \mathrm{~K}}-\mathrm{BSA}^{-}$ was detected by subsequent addition of $5 \mu \mathrm{g} \mathrm{mL}^{-1} 6.3$ anti-PEG backbone $\mathrm{Ab}$ for $1 \mathrm{~h}$, and $0.4 \mu \mathrm{g} \mathrm{mL} \mathrm{mL}^{-1} \mathrm{HRP}$-conjugated goat anti-mouse IgG Fc. The plates were washed with PBS, and bound peroxidase activity was measured by adding $150 \mu \mathrm{L}$ well ${ }^{-1}$ of ABTS solution ( $\mathrm{pH} 4.0$ ) and $0.003 \%(\mathrm{v} / \mathrm{v}) \mathrm{H}_{2} \mathrm{O}_{2}$ for $40 \mathrm{~min}$ at RT. Color development was measured at $405 \mathrm{~nm}$ on a EZ Read 400 ELISA. In order to examine whether the $\mathrm{mPEG} \times$ HER2 can simultaneously bind to $\mathrm{mPEG}$ and HER2 antigen, $\mathrm{mPEG} \times$ HER2- or $\mathrm{mPEG} \times \mathrm{DNS}$-modified PLD were incubated with SKOV-3 (HER2 ${ }^{+}$) or MDA-MB-468 (HER2-)-seeded 96-well culture plate, followed by staining with $5 \mu \mathrm{gL}^{-1}$

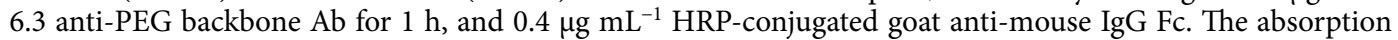
value of HRP reaction was detected by the same procedure as mentioned above.

Flow cytometry. Internalization of $\mathrm{mPEG} \times$ HER2-modified nanoparticles into HER2 ${ }^{+}$cancer cells was analyzed by adding $2 \mu \mathrm{g} \mathrm{mL} \mathrm{mL}^{-1}$ of Lipo-DiD, mPEG $\times$ DNS-modified Lipo-DiD or mPEG $\times$ HER2-modified Lipo-DiD in staining buffer (PBS containing $0.05 \%(\mathrm{w} / \mathrm{v}) \mathrm{BSA}$ ) to $2 \times 10^{5} \mathrm{SKOV}-3$ cells for $40 \mathrm{~min}$ at $4{ }^{\circ} \mathrm{C}$. After extensive washing, the cells were transferred to fresh culture medium and incubated for 1,6 and $12 \mathrm{~h}$ at $37^{\circ} \mathrm{C}$. The surface BsAb-modified Lipo-DiD on the SKOV-3 cells was determined by sequentially adding $10 \mu \mathrm{gL}^{-1}$ 6.3 anti-PEG Ab for $30 \mathrm{~min}$ and $4 \mu \mathrm{g} \mathrm{mL} \mathrm{m}^{-1}$ FITC-conjugated goat anti-mouse IgG Fc $\gamma$. After washing, the FITC signal was measured with a Cytomics FC500 flow cytometer (Beckman Coulter, CA, USA).

Western blot. SKOV-3 cancer cells $\left(2 \times 10^{5}\right)$ were seeded in a 96 -well cell culture plate at $37^{\circ} \mathrm{C}$ overnight. The next day, the cells were incubated with serum free medium (Control), $8 \mu \mathrm{g} \mathrm{mL}^{-1}$ of PLD, mPEG $\times$ HER2 $\mathrm{BsAb}$, mPEG $\times$ HER2-, mPEG $\times$ DNS-modified PLD or $80 \mathrm{ng} \mathrm{mL}{ }^{-1}$ doxorubicin at $37^{\circ} \mathrm{C}$ for $24 \mathrm{~h}$. The cells were extracted with radioimmune precipitation assay (RIPA) buffer and an equal amount of proteins were separated on SDS-PAGE and then transferred to NC membranes. The membrane was blocked with PBS containing 5\% $(\mathrm{w} / \mathrm{v})$ skim milk (BD) and incubated with specific primary antibodies against poly (ADP-ribose) polymerase (PARP), cleaved caspase 9 or $\beta$-actin, respectively, for $1 \mathrm{~h}$. After washing, appropriated HRP-conjugated goat anti-mouse IgG Fc (Jackson ImmunoResearch Laboratories, Westgrove, PA, USA) or HRP-conjugated goat antirabbit IgG $(\mathrm{H}+\mathrm{L})$ (Jackson ImmunoResearch Laboratories, Westgrove, PA, USA) were stained and incubated for $1 \mathrm{~h}$ at room temperature (RT), and expression of protein was detected using an ECL kit (Millipore, Temecula, CA, USA) and ChemiDoc MP Imaging System (Bio-red). The density of each band were quantified by ImageJ software.

Confocal microscopy of MPEG $\times$ HER2-modified PLD. To analyze the internalization of $\mathrm{mPEG} \times$ HER2-modified PLD into HER2 + cancer cells, we seeded $2 \times 10^{5} \mathrm{SKOV}-3$ cells on $2 \mu \mathrm{g} \mathrm{mL} \mathrm{m}^{-1}$ poly-L-lysine-coated glass slides at $37^{\circ} \mathrm{C}$ in a humidified atmosphere of $5 \% \mathrm{CO}_{2}$ for $24 \mathrm{~h}$. The cells were incubated with $0.5 \mathrm{mg} \mathrm{mL}^{-1}$ Hoechst 33,342 (Invitrogen, Carlsbad, CA, USA) and $50 \mathrm{nmol}$ of LysoTracker Green DND-26 in DMEM to stain the nucleus and lysosomes, respectively, for $40 \mathrm{~min}$ at $37^{\circ} \mathrm{C}$. After extensive washing with fresh culture medium, the cells were stained with $0.01 \mathrm{nmol}$ of $\mathrm{mPEG} \times \mathrm{DNS}$-modified Lipo-DiD or mPEG $\times$ HER2modified Lipo-DiD in fresh culture medium at $37^{\circ} \mathrm{C}$. The fluorescence signals were monitored in real time with a Zeiss LSM780 laser-scanning microscope (Carl Zeiss AG, Oberkochen, Germany). To detect the PLD accumulated in tumor tissue, the SKOV-3 tumor-bearing BALB/c nude mice were separately and intravenously injected with $5 \mathrm{mg} \mathrm{kg}^{-1}$ of PLD, mPEG $\times$ DNS-modified PLD or mPEG $\times$ HER2-modified PLD. Tumors were collected at $48 \mathrm{~h}$ post-injection and embedded in Tissue-Tek OCT Compound (Sakura Finetek USA, Torrance, CA, USA) at $-80{ }^{\circ} \mathrm{C}$ overnight. The nuclei were stained with DAPI fluoromount-G (Southern Biotech, Birmingham, AL, USA) and the fluorescent signals of doxorubicin and DAPI were observed under an Olympus FluoView FV1000 confocal microscope (Olympus Imaging America, Shinjuku City, Tokyo, Japan).

In vitro cytotoxicity. SKOV-3 cancer cells $\left(3 \times 10^{3}\right)$ were seeded in a 48 -well cell culture plate at $37^{\circ} \mathrm{C}$ overnight. The next day, the cells were incubated with serum free medium (Control) or serial dilutions of PLD, mPEG $\times$ DNS-modified PLD or mPEG $\times$ HER2-modified PLD $\left(100 \mu \mathrm{L}\right.$ well $\left.{ }^{-1}\right)$ at $37^{\circ} \mathrm{C}$ for $12 \mathrm{~h}$ and then the medium was replaced with fresh medium. The cell viability was measured with the ATPlite luminescence assay system (PerkinElmer, Waltham, MA) 96 h post drug treatment. As previous study described ${ }^{23}$, the results are expressed as percentage inhibition of luminescence as compared with untreated cells and calculated by the following formula: $\%$ cell viability $=100 \times$ (treated luminescence/untreated luminescence). The standard deviation for each point was averaged over four samples $(n=3)$. 
In vivo optical imaging. SKOV-3 tumor-bearing BALB/c nude mice were separately and intravenously injected with $10 \mathrm{nmol} \mathrm{mPEG} \times$ DNS-modified Lipo-DiR or $\mathrm{mPEG} \times$ HER2-modified Lipo-DiR when the tumor size was $200 \mathrm{~mm}^{3}$. The fluorescent signal of Lipo-DiR was monitored by IVIS spectrum optical imaging system (excitation, $750 \mathrm{~nm}$; emission, $780 \mathrm{~nm}$; PerkinElmer, Waltham, MA, USA) at 24, 48 and $72 \mathrm{~h}$ post-injection. The tumors and different organs (liver, spleen, heart, lung, ovary and kidney) of each group were collected at $72 \mathrm{~h}$ after Lipo-DiR injection. As previous study described ${ }^{23}$, the region of interest (ROI) in tumors or different organ areas were drawn and analyzed with Living Image software version 4.2 (Caliper Life Sciences).

In vivo antitumor therapy. SKOV-3 tumor-xenografted BALB/c nude mice were intravenously injected with saline, $5 \mathrm{mg} \mathrm{kg}^{-1}$ PLD, mPEG $\times$ HER2 BsAb, mPEG $\times$ HER2- or mPEG $\times$ DNS-modified PLD when the tumor size was $150 \mathrm{~mm}^{3}$, once a week for 4 weeks. The tumor volume was monitored using calipers every 3 days post-treatment and the tumor sizes were calculated using the following formula: volume $=\left(\right.$ length $\times$ width $\left.^{2}\right) / 2$. The body weight of the mice in each group was measured twice a week post-treatment.

Statistical analysis. Statistical significance of differences between mean values was estimated by GraphPad Prism v.6 (GraphPad Software, San Diego, CA, U.S.A.) using the repeated measures unpaired $t$ test. Data were considered significant at a $\mathrm{P}$ value of less than 0.05 .

\section{Results}

Dual function of humanized BsAb (mPEG $\times$ HER2). To generate a BsAb that can simultaneously bind to $m$ PEG and HER2 antigen, we constructed $m P E G \times$ HER 2 as described in our previous study ${ }^{23}$. We fused a Fab fragment of the humanized anti-mPEG antibody $15-2 b$, which can specifically target the methoxy-end of mPEG $^{17}$ to an anti-HER2 scFv by linking with a flexible linker (Fig. 1A). The $\mathrm{mPEG} \times \mathrm{DNS}$ was also constructed as a negative control by replacing the anti-HER2 scFv to anti-dansyl (DNS) scFv, which can bind to a small chemical hapten dansyl $l^{25}$ that is not present on the surface of cancer cells. We further analyzed the antigen binding ability of $\mathrm{mPEG} \times$ HER 2 and $\mathrm{mPEG} \times \mathrm{DNS}$ by $\mathrm{mPEG}$-based or HER2 ${ }^{+}$cell-based ELISA, respectively. Figures $1 \mathrm{~B}$ and

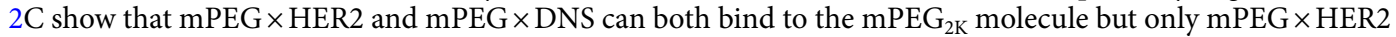
can specifically bind to HER2 antigen on the surface of HER2 ${ }^{+}$ovarian cancer cells (SKOV-3)(Fig. 1C). To examine whether the $\mathrm{mPEG} \times$ HER2 can simultaneously binding to $\mathrm{mPEG}$ and HER2 antigen, sandwich cellbased ELISA was performed by immobilizing SKOV-3 (HER2 ${ }^{+}$) cells on a 96-well cell culture plate, followed by subsequent incubation with $\mathrm{mPEG} \times \mathrm{HER} 2$ or $\mathrm{mPEG} \times \mathrm{DNS}, \mathrm{mPEG}_{2 \mathrm{~K}}-\mathrm{BSA}$, anti-PEG monoclonal Ab 6.3 and HRP-conjugated secondary Ab. Figure $1 \mathrm{D}$ shows that only $\mathrm{mPEG} \times \mathrm{HER} 2$ - but not $\mathrm{mPEG} \times \mathrm{DNS}$ can simultaneously bind to SKOV-3 cells and mPEGylated molecules (i.e., $\mathrm{mPEG}_{2 \mathrm{~K}}$-BSA) in a dose-dependent manner (Fig. 1D). In order to examine whether the $\mathrm{mPEG} \times$ HER2 can confer PLD to HER2 specificity, sandwich cellbased ELISA was performed by immobilized SKOV-3 (HER2 ${ }^{+}$) or MDA-MB-468 (HER2-) cells into a 96-well cell culture plate, followed by subsequent incubation with $\mathrm{mPEG} \times \mathrm{HER} 2^{-}$or $\mathrm{mPEG} \times \mathrm{DNS}$-modified PLD, antiPEG monoclonal Ab 6.3 and HRP-conjugated secondary Ab. Figure 1E shows that only mPEG $\times$ HER2 ${ }^{-}$but not $\mathrm{mPEG} \times \mathrm{DNS}$-modified PLD can bind to SKOV-3 cells in a dose-dependent manner (Fig. 1E) and neither mPEG $\times$ HER2 ${ }^{-}$nor $\mathrm{mPEG} \times$ DNS-modified PLD was bound to MDA-MB- 468 cells $($ Fig. $1 \mathrm{~F})$. These results indicate that $\mathrm{mPEG} \times$ HER2 can simultaneously recognize the $\mathrm{mPEG}$ molecule and HER2 antigen, provide HER2 tropism to PLD, and specifically target to HER2-overexpressed ovarian cancer cells.

Internalization of $\mathrm{mPEG} \times$ HER2-modified PLD into HER2 ${ }^{+}$cancer cells via receptor-mediated endocytosis. To investigate the internalization ability and efficiency of mPEG $\times$ HER2-modified PLD to HER2 ${ }^{+}$-overexpressed ovarian cancer cells, we modified $\mathrm{mPEG} \times$ HER2 or $\mathrm{mPEG} \times \mathrm{DNS}$ to Lipo-DiD, which is a mPEGylated nanoparticle that can exert red fluorescent signals after excitation, and tracked the fluorescent signals after incubating with HER2 ${ }^{+}$SKOV-3 cells for different time periods (1, 6 and $12 \mathrm{~h}$ ) by flow cytometry and live cell imaging system. Figure $2 \mathrm{~A}$ shows that the $\mathrm{mPEG} \times$ HER2-modified Lipo-DiD on HER2 ${ }^{+}$the ovarian cancer cell surface was gradually decreased in a time-dependent manner after incubation with Lipo-DiD and no surface Lipo-DiD was detected in the $\mathrm{mPEG} \times \mathrm{DNS}$-modified Lipo-DiD group (Fig. $2 \mathrm{~A}$ ). In contrast, the total Lipo-DiD signal obtained from different compartments of cells were similar at different time points (Fig. $2 \mathrm{~B}$ ), indicating that the initial targeted level of $\mathrm{mPEG} \times \mathrm{HER}^{-}$or $\mathrm{mPEG} \times \mathrm{DNS}$-modified Lipo-DiD to SKOV -3 cells were almost the same in each corresponding groups. These results indicate that mPEG $\times$ HER2modified Lipo-DiD can specifically target HER2 ${ }^{+}$ovarian cancer cells and efficiently trigger endocytosis within $6 \mathrm{~h}$. In live cell imaging, the mPEG $\times$ HER2-modified Lipo-DiD was incubated with HER2 + SKOV-3 for different time periods $(1-3 \mathrm{~h})$ and the fluorescence of lysosomes (green), Lipo-DiD (red) and co-localized signal (yellow) were observed by real-time confocal microscopy to monitor its binding, internalization and location in cells. Figure $2 \mathrm{C}$ shows that the bound $\mathrm{mPEG} \times$ HER2-modified Lipo-DiD was internalized at $1 \mathrm{~h}$ and fused with lysosomes (yellow signal) within $2 \mathrm{~h}$ and the co-localized signal (yellow) was gradually increased in a timedependent manner post-incubation; however, no Lipo-DiD signal was detected in the mPEG $\times$ DNS-modified Lipo-DiD group (Fig. 2C). We further analyzed the internalization ability of different dosage of mPEG $\times$ HER2modified Lipo-DiD to HER2 ${ }^{+}$SKOV-3 cells, we tracked the fluorescent signals after incubating different concentration of $\mathrm{mPEG} \times$ HER2-modified Lipo-DiD $\left(4\right.$ or $\left.8 \mu \mathrm{g} \mathrm{mL} \mathrm{mL}^{-1}\right)$ with HER2 ${ }^{+}$SKOV-3 cells for $12 \mathrm{~h}$ by flow cytometry. The results showed that the cell surfaced mPEG $\times$ HER2-modified Lipo-DiD on SKOV-3 cells were gradient increased in dose-dependent manner and they can all be internalized into the cells after transferred the BsAb-modified Lipo-DiD-labeled SKOV-3 cells from 4 to $37^{\circ} \mathrm{C}$ for $12 \mathrm{~h}$ (Supplementary Figure S2). These results suggest that $\mathrm{mPEG} \times$ HER2-modified nanoparticles can trigger efficient internalization and accumulation via receptor-mediated endocytosis in HER2-overexpressed ovarian cancer cells. 
(A)
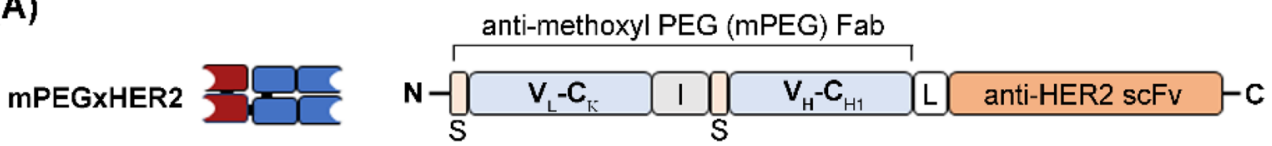

mPEGXDNS
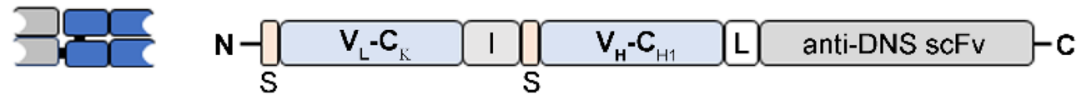

(B)

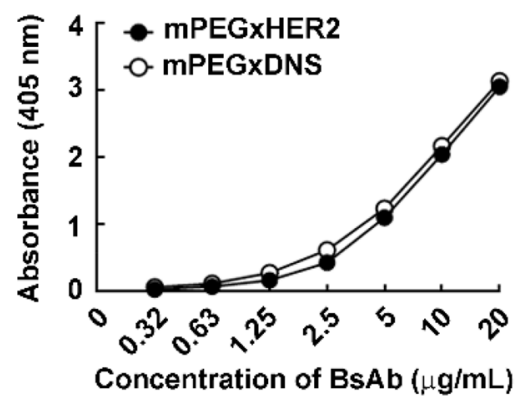

(C)

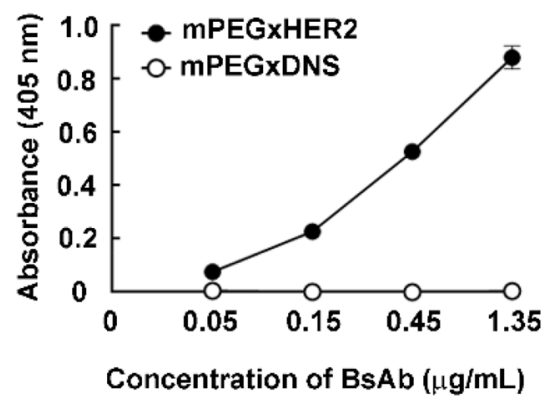

(D)

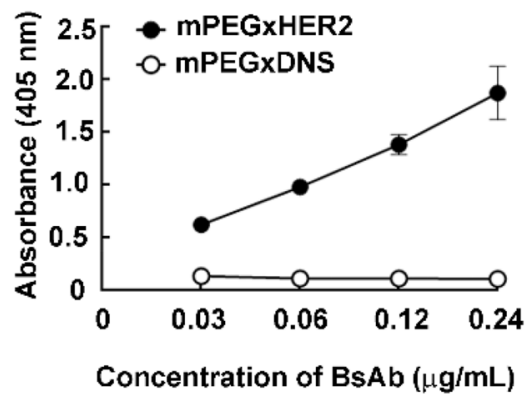

(E)

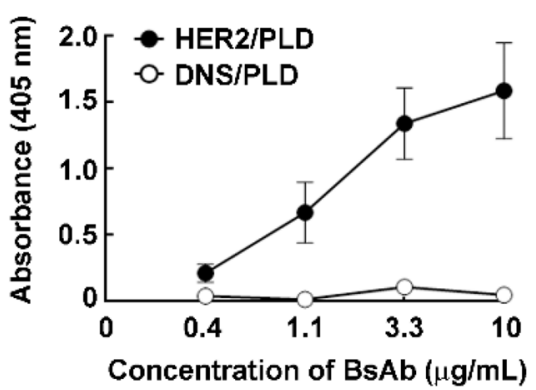

(F)

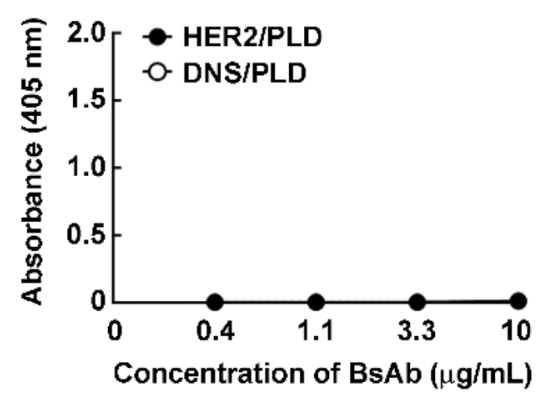

Figure 1. Characterization of $\mathrm{mPEG} \times$ HER2. (A) The gene constructs of $\mathrm{mPEG} \times$ HER 2 and $\mathrm{mPEG} \times \mathrm{DNS}$ are composed of a signal peptide (S), the anti-mPEG $\mathrm{V}_{\mathrm{L}}-\mathrm{C}_{\mathrm{k}}$, the anti-mPEG $\mathrm{V}_{\mathrm{H}}-\mathrm{C}_{\mathrm{H}}$, a flexible linker peptide (L) and an anti-HER2 scFv (mPEG $\times$ HER2) or control anti-DNS scFv $(m P E G \times D N S)$. I, internal ribosomal entry site (IRES). The (B) $\mathrm{mPEG}$ and (C) HER2 binding functions of $\mathrm{mPEG} \times$ HER2 (filled circle) or mPEG $\times$ DNS (open circle) on mPEGylated protein and HER2 ${ }^{+}$cancer cells were detected via ELISA $(\mathrm{n}=2)$. Bars, SD. (D) The simultaneous binding ability of $\mathrm{mPEG}$ and HER 2 antigen of $\mathrm{mPEG} \times$ HER 2 (filled circle) and $\mathrm{mPEG} \times \mathrm{DNS}$ (open circle) were analyzed by targeting SKOV-3 $\left(\mathrm{HER}^{+}\right)$cells and detected via cell-based ELISA $(\mathrm{n}=4)$. Bars, $\mathrm{SD}$. The specific targeting ability of $\mathrm{mPEG} \times \mathrm{HER}^{-}$(filled circle, HER2/PLD) and $\mathrm{mPEG} \times \mathrm{DNS}$-modified PLD (open circle, DNS/PLD) were analyzed by targeting (E) SKOV-3 (HER2 ${ }^{+}$) or (F) MDA-MB-468 (HER2 ${ }^{-}$) cells and detected via cell-based ELISA $(\mathrm{n}=4)$. Bars, SD.

Cytotoxicity of mPEG $\times$ HER2-modified PLD to HER2-overexpressed ovarian cancer cells. In order to analyze the cytotoxicity of $\mathrm{mPEG} \times$ HER2-modified PLD to HER2-overexpressed ovarian cancer cells, we incubated HER2 ${ }^{+}$SKOV- 3 cells with different concentrations of PLD, mPEG $\times$ HER2 $2^{-}$or mPEG $\times$DNSmodified PLD for $12 \mathrm{~h}$, followed by removing the drug, and washing the cells. The cell viability was determined by ATPlite assay $96 \mathrm{~h}$ post-drug addition. Figure 3A indicates that mPEG $\times$ HER2-modified PLD $\left(\mathrm{IC}_{50}=160 \mathrm{ng} \mathrm{mL}{ }^{-1}\right)$ significantly reduced the cell viability of SKOV-3 from a drug concentration of $40 \mathrm{ng} \mathrm{mL}^{-1}$ as compared with $\mathrm{mPEG} \times \mathrm{DNS}$-modified PLD $\left(\mathrm{IC}_{50}=870 \mathrm{ng} \mathrm{mL} \mathrm{m}^{-1}\right)$ and the PLD group $\left(\mathrm{IC}_{50}=900 \mathrm{ng} \mathrm{mL}^{-1}\right)$ and showed approximately 5.4-fold enhanced toxicity in comparison with non-targeted PLD (Fig. 3A). As expected, there was no difference between $\mathrm{mPEG} \times$ DNS-modified PLD and unmodified PLD (Fig. 3A). We also compared the cytotoxicity of $\mathrm{mPEG} \times \mathrm{HER} 2 \mathrm{BsAb}$ and anti-HER2 antibody (i.e. Trastuzumab) to SKOV-3 cell line. Both of mPEG $\times$ HER 2 BsAb and Trastuzumab were showed only $10 \%$ reduced viability of SKOV-3 cell line (Supplementary Figure S3), indicating that the significantly elevated toxicity of HER2/PLD was contributed by the specific targeting ability of $m P E G \times$ HER2 $B s A b$. To study whether the enhanced cytotoxicity of mPEG $\times$ HER2modified PLD is through inducing stronger apoptosis pathway, we treated $8 \mu \mathrm{g} \mathrm{mL}{ }^{-1} \mathrm{PLD}, \mathrm{mPEG} \times \mathrm{HER} 2 \mathrm{BsAb}$, $\mathrm{mPEG} \times \mathrm{HER}^{-}, \mathrm{mPEG} \times \mathrm{DNS}$-modified PLD or $80 \mathrm{ng} \mathrm{mL}{ }^{-1}$ doxorubicin for $24 \mathrm{~h}$ and the apoptotic marker proteins [i.e. poly (ADP-ribose) polymerase (PARP) and caspase 9] were further be detected by western blot. Figure $3 \mathrm{~B}$ shows that the PARP and caspase 9 were all increased in $\mathrm{MPEG} \times$ HER2-modified PLD-treated group 
Figure 2. $\mathrm{mPEG} \times$ HER2 improves the internalization of $\mathrm{mPEGylated} \mathrm{nanoparticles} \mathrm{into} \mathrm{HER2}{ }^{+}$ovarian cancer cells. The internalization ability of $\mathrm{mPEG} \times$ HER2-modified nanoparticles was performed by incubating mPEG $\times$ DNS-modified Lipo-DiD (DNS/Lipo-DiD) or mPEG $\times$ HER2-modified Lipo-DiD (HER2/Lipo-DiD) to HER2 ${ }^{+}$SKOV-3 cells at $4{ }^{\circ} \mathrm{C}$ for $12 \mathrm{~h}$ (green), $37^{\circ} \mathrm{C}$ for 1 (orange), 6 (blue) and $12 \mathrm{~h}$ (red) and the surface bound mPEGylated nanoparticles were detected by staining with 6.3 anti-PEG antibody and FITC-conjugated secondary $\mathrm{Ab}$ and analyzed by flow cytometry. The internalized Lipo-DiD in SKOV-3 cells were evaluated by monitoring the (A) decreasing level of surface FITC signal. The (B) total mPEGylated nanoparticles (including surface and internalized Lipo-DiD) were monitored by detecting the red fluorescent signal of Lipo-DiD. The gray peak on the graphs show mock staining with PBS containing $0.05 \%$ (wt/vol) BSA. (C) The internalization process of $\mathrm{mPEG} \times$ HER2-modified Lipo-DiD was investigated by confocal live cell imaging system. The HER $2^{+}$ SKOV-3 cells were stained with Hoechst 33342 (blue), LysoTracker (green) and mPEG $\times$ DNS $^{-}$(DNS/Lipo-DiD) or mPEG $\times$ HER2-modified Lipo-DiD (HER2/Lipo-DiD) (red). The co-localization of Lipo-DiD with lysosome (yellow) in SKOV-3 cells was observed in real time by confocal microscopy. Scale bar $40 \mu \mathrm{m}$.

as compared with $\mathrm{mPEG} \times$ DNS-modified PLD or PLD group. The expression level of apoptotic marker proteins (PARP and Caspase 9) in $\mathrm{mPEG} \times$ HER2 BsAb-treated group showed no significant difference as compared with untreated group (Fig. $3 \mathrm{~B}$ ). These results suggest that the $\mathrm{mPEG} \times$ HER2-modified PLD improved the cytotoxicity of PLD in HER2-overexpressed ovarian cancer cells through triggering stronger apoptosis pathway.

Specific targeting and accumulation of mPEG $\times$ HER2-modified PLD to HER2 ${ }^{+}$-overexpressed tumors. To investigate the specific targeted ability and accumulated efficiency of mPEG $\times$ HER2-modified nanoparticle drug to HER2-overexpressed ovarian tumor in vivo, we established a human ovarian carcinomaxenografted model by subcutaneously inoculating HER2 ${ }^{+}$SKOV-3 cells at the hind foot of nude mice and intravenously treating with $\mathrm{mPEG} \times \mathrm{HER} 2^{-}$or $\mathrm{mPEG} \times \mathrm{DNS}$-modified far red-labeled liposomes (PEGylated liposomal DiR; Lipo-DiR), respectively, when tumor size had grown to $200 \mathrm{~mm}^{3}$. The red fluorescent signal of Lipo-DiR was detected by IVIS imaging system at 24,48 and $72 \mathrm{~h}$ post-injection. Figure $4 \mathrm{~A}$ shows that the mPEG $\times$ HER2-modified Lipo-DiR can more specifically target to HER2 ${ }^{+}$ovarian tumors as compared with $\mathrm{mPEG} \times \mathrm{DNS}$-modified Lipo-DiR. The quantitative signal of the region of interest $(\mathrm{ROI})$ of $\mathrm{mPEG} \times \mathrm{HER} 2$ modified Lipo-DiR-treated tumors was increased by $140 \%\left(9.1 \times 10^{9}\right.$ versus $\left.6.5 \times 10^{9}\right), 140 \%\left(7.8 \times 10^{9}\right.$ versus $\left.5.6 \times 10^{9}\right)$ and $240 \%\left(6.1 \times 10^{9}\right.$ versus $\left.2.6 \times 10^{9}\right)$ at 24,48 and $72 \mathrm{~h}$, respectively, as compared with mPEG $\times$ DNSmodified Lipo-DiR (Fig. 4B). The mice were further sacrificed and the organs (liver, spleen, heart, lung, ovary and kidney) were collected at $72 \mathrm{~h}$ post-injection to monitor the biodistribution of targeted Lipo-DiR. Figure 4C indicates that the targeted Lipo-DiR was preferentially accumulated in tumor tissue and non-specifically accumulated in liver and spleen tissue, which are major metabolic organs for nanoparticle drugs ${ }^{26,27}$. In order to evaluate whether mPEG $\times$ HER2-modified PLD can efficiently enter into the nucleus of HER2 ${ }^{+}$ovarian tumor cells, we further intravenously treated PLD, $\mathrm{mPEG} \times$ HER2- or $\mathrm{mPEG} \times$ DNS-modified PLD to SKOV-3-xenografted nude mice and collected the tumor tissue for detecting the doxorubicin signal at $48 \mathrm{~h}$ after drug treatment. As shown in Fig. 4D, there was more red fluorescence of doxorubicin signal accumulated at the HER2 ${ }^{+}$ovarian tumor region and colocalized with the nucleus of tumor cells than for the $\mathrm{mPEG} \times \mathrm{DNS}$-modified PLD or PLD control group. These results indicate that $\mathrm{MPEG} \times$ HER2-modified nanoparticles can more efficiently target and accumulate to HER2 ${ }^{+}$ovarian tumor than non-targeted PLD.

Therapeutic efficacy of mPEG $\times$ HER2-modified PLD in HER2 ${ }^{+}$tumor-xenografted nude mice. To investigate the therapeutic efficacy of $\mathrm{mPEG} \times$ HER2-modified PLD to HER2-overexpressed ovarian tumor in vivo, we established SKOV-3 tumor-bearing nude mice and intravenously treated them with saline, $5 \mathrm{mg} \mathrm{kg}^{-1}$ PLD, mPEG $\times$ HER2 BsAb, mPEG $\times$ HER2 ${ }^{-}$or $\mathrm{mPEG} \times \mathrm{DNS}$-modified PLD once a week for 4 weeks and the tumor volume and body weight of tumor-bearing mice was measured twice a week. Figure $5 \mathrm{~A}$ shows that the $\mathrm{mPEG} \times$ HER2-modified PLD can significantly inhibit the HER2 ${ }^{+}$ovarian tumor growth as compared to treatment with $\mathrm{mPEG} \times \mathrm{DNS}$-modified PLD $(P=0.0319)$ or PLD $(P=0.0437)$ and there was no significant difference between $m P E G \times D N S$-modified PLD- and PLD-treated groups $(P=0.5754)$ (Fig. 5A). There was no significant change in the body weight of each treated group (Fig. $5 \mathrm{~B}$ ). These results demonstrate that mPEG $\times$ HER2modified PLD can enhance the therapeutic efficacy of PLD to HER2-overexpressed ovarian cancer with minimal obvious toxicity.

\section{Discussion}

In this study, we successfully developed a BsAb $(\mathrm{mPEG} \times$ HER2) which can simultaneously recognize mPEG molecules on the surface of mPEGylated nanomedicine (i.e., PLD) and the HER2 antigen on the surface of ovarian cancer cells, and easily provide HER2 ${ }^{+}$tumor specificity to PLD by a simple mixing procedure. We demonstrated that the mPEG $\times$ HER2-modified PLD can significantly enhance its tumor targeted specificity, endocytic efficiency and cytotoxicity to HER2-overexpressed SKOV-3 cells and also increase its accumulation and anti-cancer activity in a HER2 ${ }^{+}$tumor-xenografted mouse model. We believe that $\mathrm{mPEG} \times$ HER2-modified PLD can elevate susceptibility of ovarian cancer cells to PLD and eliminate residual cancer cells, thereby decreasing the frequency of relapse disease to achieve more effective targeted therapy of ovarian cancer. The design of the anti-tumor marker arm in the BsAb can also be changed to other antibodies to lead PLD or other mPEGylated drugs to target a various types of malignancies in the future.

Targeted liposomal drugs with enhanced endocytic ability can dramatically improve the drug susceptibility, cytotoxicity and therapeutic efficacy of malignancies. Wu and colleagues demonstrated that liposomal 
(A)
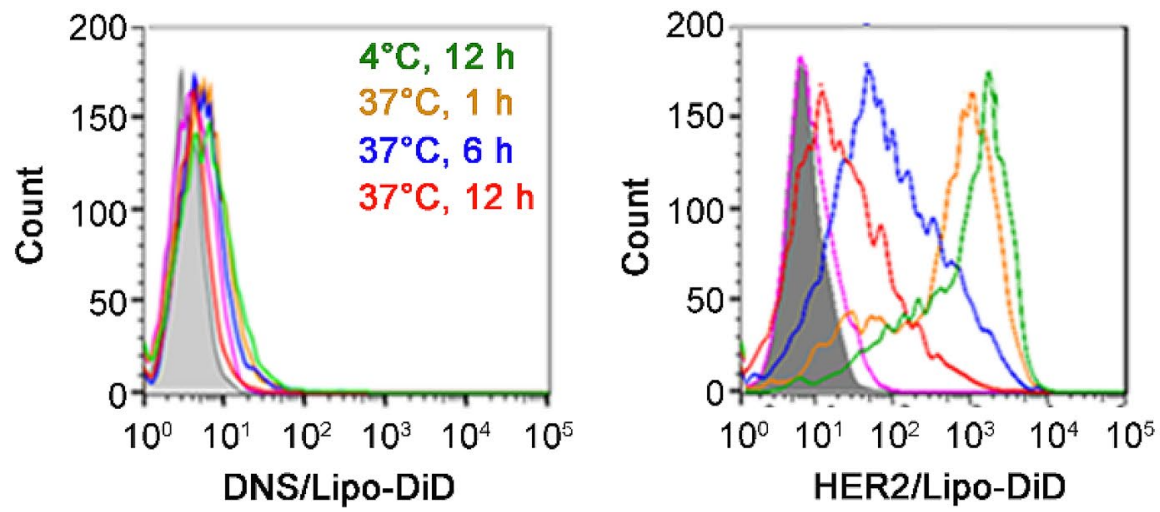

(B)
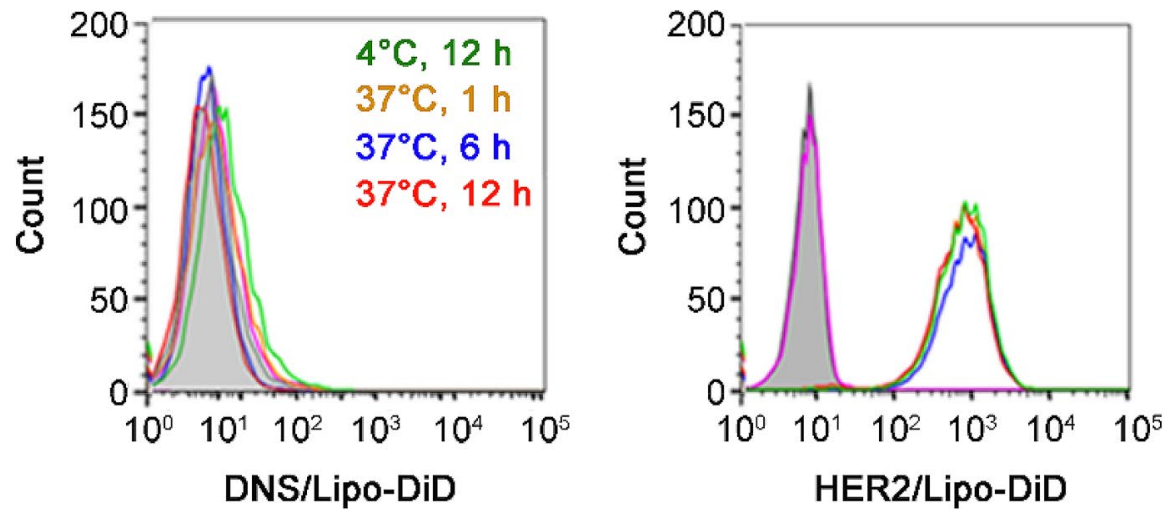

(C)
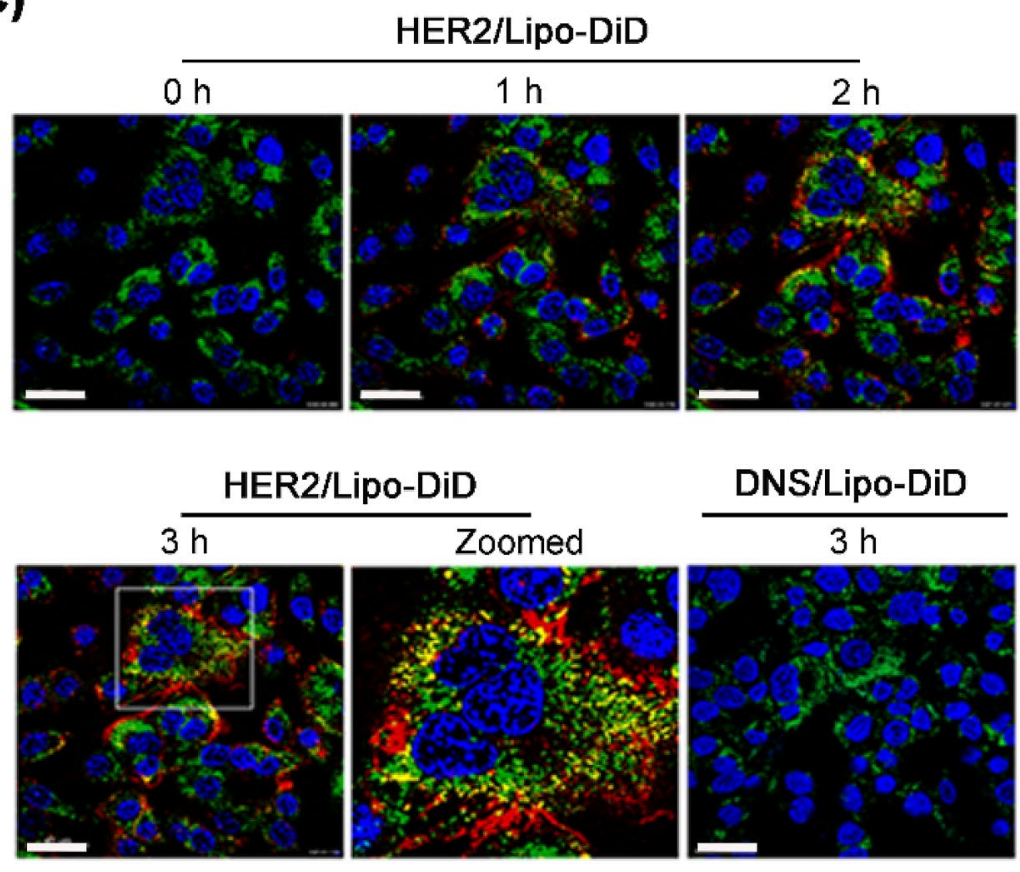
(A)

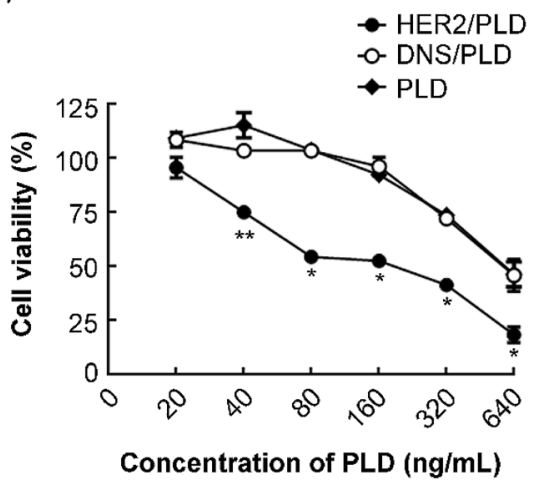

(B)

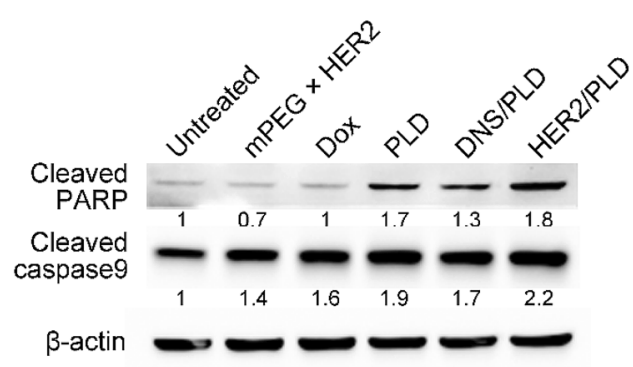

Figure 3. $m P E G \times$ HER2 enhances the cytotoxicity of PLD to HER2 ${ }^{+}$ovarian cancer through triggering apoptosis pathway. (A) PLD (filled diamond), mPEG $\times$ DNS-modified PLD (open circle, DNS/PLD) or mPEG $\times$ HER2-modified PLD (filled circle, HER2/PLD) were incubated with SKOV-3 ovarian cancer cells for $12 \mathrm{~h}$. The cell viability was determined by ATPlite analysis and the mean luminescence values compared to untreated control cells $(\mathrm{n}=3)$. Bars, SD. ${ }^{*} P<0.05 .{ }^{*} P<0.01$. (B) $\mathrm{mPEG} \times$ HER2, Dox, PLD, DNS/PLD or HER2/ PLD were incubated with SKOV-3 ovarian cancer cells for $24 \mathrm{~h}$. The apoptotic marker proteins (i.e. PARP and Caspase 9) were analyzed by Western blot and the relative ratio of apoptotic marker proteins to $\beta$-actin is shown below each lane. The cell lysates of each treated group were analyzed as described above. Lane 1, untreated group was used as a negative control. Dox, doxorubicin.

doxorubicin (LD) conjugated with pHCT74 peptide, which can specifically target to a-enolase (ENO1) on the surface of cancer cells and trigger endocytosis ${ }^{28}$, exhibits a half maximal inhibitory concentration $\left(\mathrm{IC}_{50}\right)$ value of about twofold lower than nontargeted LD to colorectal cancer cells (HCT116) in vitro and significantly inhibits tumor growth by $80.1 \%$ as compared with nontargeted LD (65.8\%) in HCT116-xenografted mice ${ }^{28}$. Lu et al. also suggested that anti-c-Met scFv (Ms20)-conjugated LD (Ms20-LD) can efficiently lead the liposomal drug to bind to $\mathrm{c}$-Met receptor and induce an internalized mechanism and improve the $\mathrm{IC}_{50}$ to sixfold lower than unconjugated $\mathrm{LD}$ to lung cancer cells (H1993 and H441) ${ }^{29}$. The Ms20-LD was also proved to increase tumor accumulation rate 2.4 fold and therapeutic efficacy 1.9 fold in comparison with the LD group in human lung cancer cell (H460)xenografted SCID mice ${ }^{29}$. Similarly, our mPEG $\times$ HER2-modified PLD exhibited higher endocytic ability (Fig. 2) and cytotoxicity (Fig. 3) in HER2-overexpressed ovarian cancer cells changing the $\mathrm{IC}_{50}$ from 870 to $160 \mathrm{ng} \mathrm{mL}^{-1}$ and significantly improving the therapeutic efficacy of SKOV-3-xenografted nude mice with minimal obvious toxicity (i.e. no significant body weight changed) as compared with non-targeted control BsAb-modified PLD (Fig. 5). We expect that the MPEG $\times$ HER2-modified PLD can significantly increase the safety of targeted PLDtreated individual and susceptibility of HER2 ${ }^{+}$ovarian cancer cells to PLD, reduce the number of residual cancer cells and further decrease the frequency of relapse disease after PLD treatment.

The anti-mPEG arm of the BsAb can be easily applied to different mPEGylated nanoparticle drugs to respond to the drug tolerance or resistance of ovarian cancer. PEG, especially $\mathrm{mPEG}$, is a water-soluble, low immunogenic, non-toxic and biocompatible polymer that has been widely used in various therapeutic nanoparticles for cancer therapy ${ }^{17,18,30}$, such as mPEGylated liposomal-Doxorubicin (Lipo-Dox; Taiwan Liposome, Taiwan and Doxil/ Caelyx; Johnson and Johnson, USA) ${ }^{5,31}$, mPEGylated liposomal-Irinotecan (Onivyde; Merrimack, USA) ${ }^{32,33}$ and PEGylated liposomal-Mitomycin C (PROMITIL) in Phase I clinical trials ${ }^{34}$. In our previous study, Kao et al. suggested that the mPEG $\times$ HER2 can confer HER2 specificity to various mPEG-NPs (Lipo/IR780, FeOdots or Qdot ${ }_{565 \mathrm{~nm}}$ ) by a simple mixing procedure ${ }^{25}$ and enhance their targeting ability to SK-BR-3 (HER2 ${ }^{+}$) tumor cells, but not MDA-MB-468 (HER2 ${ }^{-}$) tumor cell ${ }^{25}$. We believe that the flexible strategy derived from one-step formulation of mPEG BsAb to mPEGylated nanoparticles can be easily transferred to other therapeutic options after the development of drug tolerance or resistance to ovarian cancer, performing uninterrupted attack on the residual cancer cells to prevent relapse disease.

The changeable design of the anti-tumor marker arm in our $\mathrm{BsAb}$ can properly shift to antibodies against different surface biomarkers to overcome the heterogenicity of ovarian cancer during treatment. Ovarian cancer is a heterogeneous tumor with five subtypes, high-grade serous (70\%), low-grade serous (5\%), endometrioid (10-15\%), clear cell (10-15\%) and mucinous (3\%) tumor ${ }^{2,9,35}$. Several potential targets have been applied in clinical therapy (e.g., vascular epithelial growth factor $(\mathrm{VEGF})^{36-38}$ ) or are under development in the preclincal stages (e.g., HER $2^{19}$, programmed cell death protein-1 (PD-1 $)^{39}$ and mesothelin ${ }^{40-42}$, etc.). Our previous study demonstrated that the modular structure of the BsAb allows generation of BsAbs with specificity to different tumor antigens [i.e., epidermal growth factor receptor (EGFR)] and actively delivers mPEGylated nanoparticles (e.g., therapeutic agents or image probes) to SW480 (EGFR ${ }^{+}$) but not SW620 (EGFR') tumor cells ${ }^{25}$. We anticipate that the changeable design of the anti-tumor marker arm of a BsAb can convert its antigen specificity to any potential surface biomarkers of different types of ovarian cancer for more comprehensive therapy.

In summary, non-covalent modification of $\mathrm{MPEG} \times$ HER2 simply confers PLD with HER2 specificity and improves its tumor targeting, endocytic ability and drug susceptibility in ovarian cancer treatment. We suggest that the BsAb-modifying strategy has the following advantagies and potential: (1) easily provides tumor 
(A)

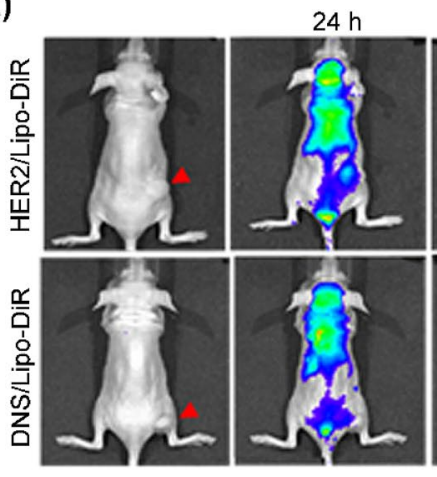

(C)

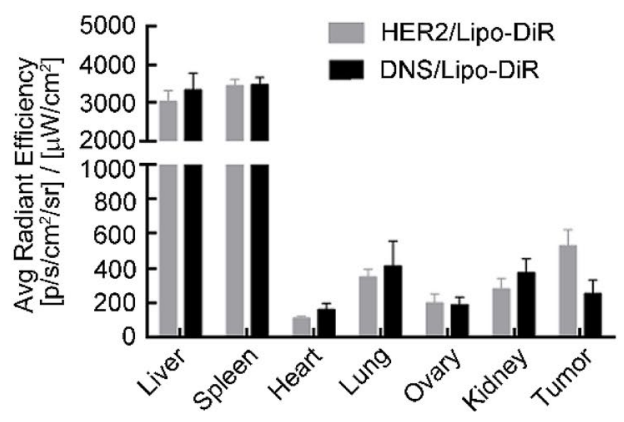

$48 \mathrm{~h}$

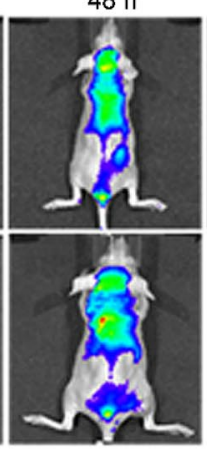

$72 \mathrm{~h}$

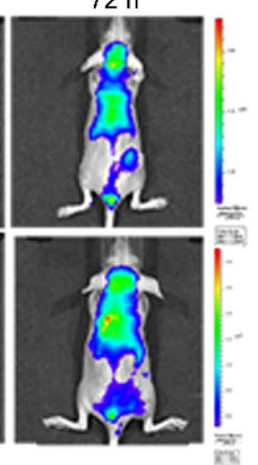

(B)

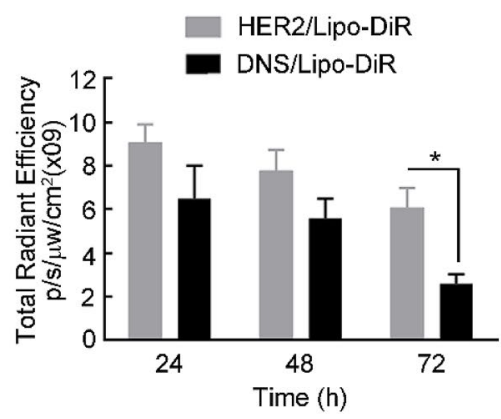

(D)
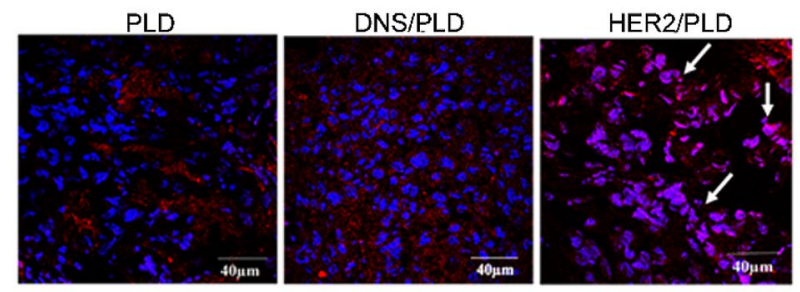

DOX DAPI

Figure 4. $\mathrm{mPEG} \times \mathrm{HER} 2$ improves the tumor targeting and accumulation of PLD in ovarian tumor tissue. (A) $\mathrm{mPEG} \times \mathrm{DNS}^{-}(\mathrm{DNS} /$ Lipo-DiR) or mPEG $\times$ HER2-modified Lipo-DiR (HER2/Lipo-DiR) were intravenously injected in SKOV-3 tumor-bearing nude mice (red arrow at right flank). The fluorescence intensity of DiR was monitored at 24,48 and $72 \mathrm{~h}$ post-injection by IVIS spectrum optical imaging system. (B) The total region of interest (ROI) in SKOV-3 tumors that were treated with $\mathrm{mPEG} \times \mathrm{DNS}^{-}$(black, DNS/Lipo-DiR) or mPEG $\times$ HER2-modified Lipo-DiR (gray, HER2/Lipo-DiR) was quantified by Living Image software. (C) The total ROI of collected tumors and different organs (liver, spleen, heart, lung, ovary and kidney) treated with $\mathrm{mPEG} \times \mathrm{DNS}^{-}$(black, DNS/Lipo-DiR) or mPEG $\times$HER2-modified Lipo-DiR (gray, HER2/Lipo-DiR) were quantified at $72 \mathrm{~h}(\mathrm{n}=5)$. Bars, SEM. ${ }^{\star} P<0.05$. (D) The accumulated effect of doxorubicin of HER2targeted PLD in ovarian tumor was measured by treating PLD, mPEG $\times$ DNS-modified PLD (DNS/PLD) or mPEG $\times$ HER2-modified PLD (HER2/PLD) to SKOV-3 tumor-bearing nude mice and detecting the fluorescent signal of doxorubicin at $48 \mathrm{~h}$ after treatment. The tumors were collected and the nucleus stained by DAPI. The fluorescent signal of doxorubicin (red) and DAPI (blue) were detected by confocal microscopy and the co-localized signals of doxorubicin and nucleus in HER2/PLD-treated mice are indicated (white arrow). Scale bar $40 \mu \mathrm{m}$.

(A)

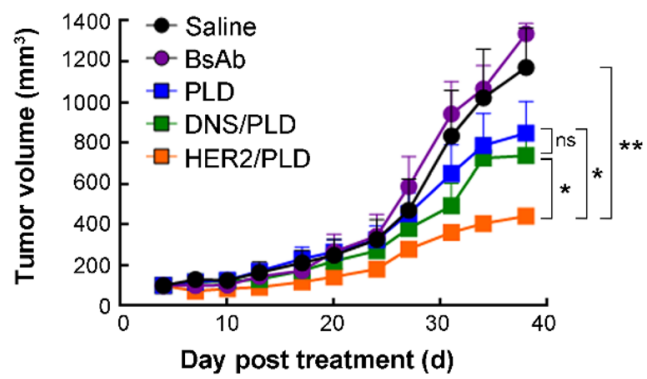

(B)

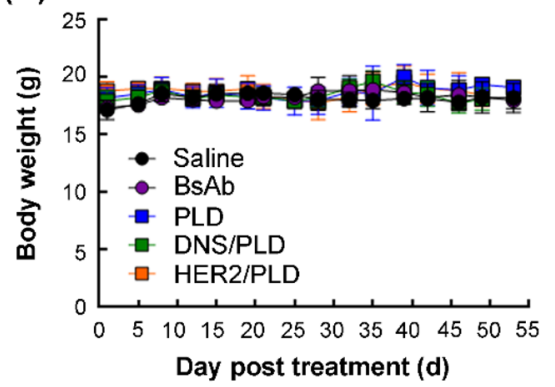

Figure 5. $m P E G \times$ HER2 improves the therapeutic efficacy of PLD HER2-overexpressed ovarian cancer. We injected $5 \mathrm{mg} \mathrm{kg}^{-1}$ of saline (black circle, $\mathrm{n}=3$ ), PLD (blue square, $\mathrm{n}=4$ ), mPEG $\times$ HER2 BsAb (violet circle, $\mathrm{n}=3$ ), $\mathrm{mPEG} \times \mathrm{HER}^{-}$(yellow square, HER2/PLD, $\mathrm{n}=4$ ) or $\mathrm{mPEG} \times$ DNS-modified PLD (green square, DNS/ PLD, $\mathrm{n}=4$ ) into SKOV-3 tumor-bearing nude mice when tumor size was $150 \mathrm{~mm}^{3}$, once a week for 4 weeks. (A) The tumor volume of each treatment and (B) the body weight were measured every 3 days post-treatment. Bars, SEM. ${ }^{*} P<0.01 .{ }^{\star} P<0.05$. ns not significant. 
specificity to mPEGylated nanomedicines by one-step and non-covalently modification of the BsAb and avoids multi-directional modification of targeted agents caused by conventional chemical conjugation; (2) the elevated susceptibility of ovarian cancer to targeted PLD may efficiently eliminate residual cancer cells after debulking surgery and further prevent the frequency of relapse disease; (3) the changeable design of our BsAb can flexibly exchange either to different tumor targeted Abs or to different mPEGylated drugs against drug resistance of ovarian cancer. We expect that the wide applicability of BsAbs (mPEG $\times$ markers) can significantly improve the therapeutic efficacy, reduce the relapse frequency and thereby achieve good prognosis in ovarian cancer patients.

Animal research. The study was carried out in compliance with the ARRIVE guidelines.

Received: 3 August 2020; Accepted: 22 March 2021

Published online: 07 April 2021

\section{References}

1. Stewart, C., Ralyea, C. \& Lockwood, S. Ovarian cancer: An integrated review. Semin. Oncol. Nurs. 35, 151-156. https://doi.org/10. 1016/j.soncn.2019.02.001 (2019).

2. Lengyel, E. Ovarian cancer development and metastasis. Am. J. Pathol. 177, 1053-1064. https://doi.org/10.2353/ajpath.2010.100105 (2010).

3. Narod, S. Can advanced-stage ovarian cancer be cured?. Nat. Rev. Clin. Oncol. 13, 255-261. https://doi.org/10.1038/nrclinonc. 2015.224 (2016).

4. Allen, T. M. \& Cullis, P. R. Liposomal drug delivery systems: From concept to clinical applications. Adv. Drug Deliv. Rev. 65, 36-48. https://doi.org/10.1016/j.addr.2012.09.037 (2013).

5. Barenholz, Y. Doxil(R) - the first FDA-approved nano-drug: Lessons learned. J. Controll. Release 160, 117-134. https://doi.org/ 10.1016/j.jconrel.2012.03.020 (2012).

6. Blanco, E., Shen, H. \& Ferrari, M. Principles of nanoparticle design for overcoming biological barriers to drug delivery. Nat. Biotechnol. 33, 941-951. https://doi.org/10.1038/nbt.3330 (2015).

7. Zou, Y., Xia, Y., Meng, F., Zhang, J. \& Zhong, Z. GE11-directed functional polymersomal doxorubicin as an advanced alternative to clinical liposomal formulation for ovarian cancer treatment. Mol. Pharm. 15, 3664-3671. https://doi.org/10.1021/acs.molph armaceut.8b00024 (2018).

8. Lawrie, T. A., Bryant, A., Cameron, A., Gray, E. \& Morrison, J. Pegylated liposomal doxorubicin for relapsed epithelial ovarian cancer. Cochrane Database Syst Rev. https://doi.org/10.1002/14651858.CD006910.pub2 (2013).

9. Gonzalez-Martin, A. \& du Bois, A. Factors to consider and questions to ask in the management of recurrent ovarian cancer: A focus on the role of trabectedin + pegylated liposomal doxorubicin. Expert Rev. Anticancer Ther. 16, 3-10. https://doi.org/10.1080/ 14737140.2016 .1243477 (2016).

10. McGuire, W. P. et al. Randomized phase II study of the PDGFRalpha antibody olaratumab plus liposomal doxorubicin versus liposomal doxorubicin alone in patients with platinum-refractory or platinum-resistant advanced ovarian cancer. BMC Cancer 18, 1292. https://doi.org/10.1186/s12885-018-5198-4 (2018).

11. Lorusso, D. et al. Treatment of recurrent ovarian cancer with pegylated liposomal doxorubicin: A reappraisal and critical analysis. Tumori 105, 282-287. https://doi.org/10.1177/0300891619839308 (2019).

12. Pastorino, F. et al. Enhanced antitumor efficacy of clinical-grade vasculature-targeted liposomal doxorubicin. Clin. Cancer Res. 14, 7320-7329. https://doi.org/10.1158/1078-0432.CCR-08-0804 (2008).

13. Ferrandina, G. et al. Phase III trial of gemcitabine compared with pegylated liposomal doxorubicin in progressive or recurrent ovarian cancer. J. Clin. Oncol. 26, 890-896. https://doi.org/10.1200/JCO.2007.13.6606 (2008).

14. Gordon, A. N. et al. Recurrent epithelial ovarian carcinoma: A randomized phase III study of pegylated liposomal doxorubicin versus topotecan. J. Clin. Oncol. 19, 3312-3322. https://doi.org/10.1200/JCO.2001.19.14.3312 (2001).

15. Gordon, A. N., Tonda, M., Sun, S., Rackoff, W. \& Doxil Study I. Long-term survival advantage for women treated with pegylated liposomal doxorubicin compared with topotecan in a phase 3 randomized study of recurrent and refractory epithelial ovarian cancer. Gynecol. Oncol. 95, 1-8. https://doi.org/10.1016/j.ygyno.2004.07.011 (2004).

16. Cheng, T. L., Chuang, K. H., Chen, B. M. \& Roffler, S. R. Analytical measurement of PEGylated molecules. Bioconjug. Chem. 23, 881-899. https://doi.org/10.1021/bc200478w (2012).

17. Lin, W. W. et al. Optimization of an anti-poly(ethylene glycol) (anti-PEG) cell-based capture system to quantify PEG and PEGylated molecules. Anal. Chem. 88, 12371-12379. https://doi.org/10.1021/acs.analchem.6b03614 (2016).

18. Lin, W. W. et al. Enhancement effect of a variable topology of a membrane-tethered anti-poly(ethylene glycol) antibody on the sensitivity for quantifying PEG and PEGylated molecules. Anal. Chem. 89, 6082-6090. https://doi.org/10.1021/acs.analchem. $7 \mathrm{~b} 00730(2017)$.

19. Bookman, M. A., Darcy, K. M., Clarke-Pearson, D., Boothby, R. A. \& Horowitz, I. R. Evaluation of monoclonal humanized antiHER2 antibody, trastuzumab, in patients with recurrent or refractory ovarian or primary peritoneal carcinoma with overexpression of HER2: A phase II trial of the Gynecologic Oncology Group. J. Clin. Oncol. 21, 283-290. https://doi.org/10.1200/JCO.2003.10. 104 (2003).

20. Wen, W. et al. Mutations in the kinase domain of the HER2/ERBB2 gene identified in a wide variety of human cancers. J. Mol. Diagn. 17, 487-495. https://doi.org/10.1016/j.jmoldx.2015.04.003 (2015).

21. Menderes, G. et al. Superior in vitro and in vivo activity of trastuzumab-emtansine (T-DM1) in comparison to trastuzumab, pertuzumab and their combination in epithelial ovarian carcinoma with high HER2/neu expression. Gynecol. Oncol. 147, 145-152. https://doi.org/10.1016/j.ygyno.2017.07.009 (2017).

22. Chen, I. J. et al. Selective antibody activation through protease-activated pro-antibodies that mask binding sites with inhibitory domains. Sci. Rep. 7, 11587. https://doi.org/10.1038/s41598-017-11886-7 (2017).

23. Cheng, Y. A. et al. Enhanced drug internalization and therapeutic efficacy of PEGylated nanoparticles by one-step formulation with anti-mPEG bispecific antibody in intrinsic drug-resistant breast cancer. Biomater. Sci. 7, 3404-3417. https://doi.org/10.1039/ c9bm00323a (2019).

24. Chuang, K. H. et al. Combination cancer therapy by hapten-targeted prodrug-activating enzymes and cytokines. Bioconjug. Chem. 17, 707-714. https://doi.org/10.1021/bc0600160 (2006).

25. Kao, C. H. et al. One-step mixing with humanized anti-mPEG bispecific antibody enhances tumor accumulation and therapeutic efficacy of mPEGylated nanoparticles. Biomaterials 35, 9930-9940. https://doi.org/10.1016/j.biomaterials.2014.08.032 (2014). 
26. Ishida, T., Kashima, S. \& Kiwada, H. The contribution of phagocytic activity of liver macrophages to the accelerated blood clearance (ABC) phenomenon of PEGylated liposomes in rats. J. Controll. Release 126, 162-165. https://doi.org/10.1016/j.jconrel.2007.11. 009 (2008)

27. Hsieh, Y. C. et al. Pre-existing anti-polyethylene glycol antibody reduces the therapeutic efficacy and pharmacokinetics of PEGylated liposomes. Theranostics 8, 3164-3175. https://doi.org/10.7150/thno.22164 (2018).

28. Wu, C. H., Kuo, Y. H., Hong, R. L. \& Wu, H. C. alpha-Enolase-binding peptide enhances drug delivery efficiency and therapeutic efficacy against colorectal cancer. Sci. Transl. Med. 7, 290ra291. https://doi.org/10.1126/scitranslmed.aaa9391 (2015).

29. Lu, R. M., Chang, Y. L., Chen, M. S. \& Wu, H. C. Single chain anti-c-Met antibody conjugated nanoparticles for in vivo tumortargeted imaging and drug delivery. Biomaterials 32, 3265-3274. https://doi.org/10.1016/j.biomaterials.2010.12.061 (2011).

30. Turecek, P. L., Bossard, M. J., Schoetens, F. \& Ivens, I. A. PEGylation of biopharmaceuticals: A review of chemistry and nonclinical safety information of approved drugs. J. Pharm. Sci. 105, 460-475. https://doi.org/10.1016/j.xphs.2015.11.015 (2016).

31. Caracciolo, G. Liposome-protein corona in a physiological environment: Challenges and opportunities for targeted delivery of nanomedicines. Nanomedicine 11, 543-557. https://doi.org/10.1016/j.nano.2014.11.003 (2015).

32. Papi, M. et al. Clinically approved PEGylated nanoparticles are covered by a protein corona that boosts the uptake by cancer cells. Nanoscale 9, 10327-10334. https://doi.org/10.1039/c7nr03042h (2017).

33. Passero, F. C. Jr., Grapsa, D., Syrigos, K. N. \& Saif, M. W. The safety and efficacy of Onivyde (irinotecan liposome injection) for the treatment of metastatic pancreatic cancer following gemcitabine-based therapy. Expert Rev. Anticancer Ther. 16, 697-703. https:// doi.org/10.1080/14737140.2016.1192471 (2016).

34. Anselmo, A. C. \& Mitragotri, S. Nanoparticles in the clinic: An update. Bioeng. Transl. Med. 4, e10143. https://doi.org/10.1002/ btm2.10143 (2019).

35. Cancer Genome Atlas Research, N. Integrated genomic analyses of ovarian carcinoma. Nature 474, 609-615. https://doi.org/10. 1038/nature10166 (2011).

36. Burger, R. A. et al. Incorporation of bevacizumab in the primary treatment of ovarian cancer. N. Engl. J. Med. 365, $2473-2483$. https://doi.org/10.1056/NEJMoa1104390 (2011).

37. Gourd, E. Olaparib plus bevacizumab improves progression-free survival in ovarian cancer. Lancet Oncol. 21, e71. https://doi.org/ $10.1016 /$ S1470-2045(20)30005-X (2020).

38. Ray-Coquard, I. et al. Olaparib plus bevacizumab as first-line maintenance in ovarian cancer. N. Engl. J. Med. 381, 2416-2428. https://doi.org/10.1056/NEJMoa1911361 (2019).

39. Hamanishi, J. et al. Safety and antitumor activity of anti-PD-1 antibody, nivolumab, in patients with platinum-resistant ovarian cancer. J. Clin. Oncol. 33, 4015-4022. https://doi.org/10.1200/JCO.2015.62.3397 (2015).

40. Ghafoor, A., Thomas, A. \& Hassan, R. Targeting mesothelin in ovarian cancer. Oncotarget 9, 36050-36051. https://doi.org/10. 18632/oncotarget.26350 (2018).

41. Hilliard, T. S. The impact of mesothelin in the ovarian cancer tumor microenvironment. Cancers https://doi.org/10.3390/cance rs10090277 (2018)

42. Yildiz, Y. et al. High expression of mesothelin in advanced serous ovarian cancer is associated with poor prognosis. J. BUON 24, 1549-1554 (2019).

\section{Acknowledgements}

This work was supported by Grants from the Ministry of Science and Technology, Taipei, Taiwan (MOST 1072320-B-037-024-MY3, MOST107-2320-B-037-028-MY2 and MOST106-2311-B-037-001-MY2, 109-2320-B-037 -010 -MY3, 109-2627-M-037 -001); the National Health Research Institutes, Taiwan (NHRI-EX107-10729EI and NHRI-EX108-10729EI); Academia Sinica, Taiwan (AS-107-TP-B11 and AS-TP-107-L11); the Program for Translational Innovation of Biopharmaceutical Development-Technology Supporting Platform Axis, Academia Sinica, Taiwan (Grant No. AS-KPQ-106-TSPA); the Ministry of Education, Taiwan (108RSB0029); the KMU-KMUH Co-Project of Key Research (KMU-DK108002 and KMU-DK109001) and Research Foundation (KMU-Q108001, KMU-Q109002, KMU-DK109004 and KMU-KI110004) from Kaohsiung Medical University, Taiwan; the CCH-KMU joint research project (108-CCH-KMU-010); the NSYSU-KMU joint research project (NK-108108); the Medical Research Fund of Kaohsiung Armed Forces General Hospital (802KB109388). We also thank the Drug Development and Value Creation Research Center, Kaohsiung Medical University, Taiwan (KMU-TC108A03) for the instrumentation and equipment support.

\section{Author contributions}

W.-W.L., Y.-A.C., C.-C.L., K.-W.H. and H.-J.C. performed the experiments. W.-W.L., Y.-A.C., H.-W.L. and T.L.C. interpreted the results. W.-W.L., Y.-A.C. and T.-L.C. wrote the manuscript. W.-W.L., H.-W.L. and T.-L.C. designed experiments and illustrated figures. K.-W.H., H.-J.C., I.-J.C., B.-C.H., H.-J.L., Y.-C.L., C.-M.C. and M.-Y.H. assisted manuscript editing and proofreading. All authors read and approved the final manuscript.

\section{Competing interests}

The authors declare no competing interests.

\section{Additional information}

Supplementary Information The online version contains supplementary material available at https://doi.org/ 10.1038/s41598-021-87271-2.

Correspondence and requests for materials should be addressed to H.-W.L. or T.-L.C.

Reprints and permissions information is available at www.nature.com/reprints.

Publisher's note Springer Nature remains neutral with regard to jurisdictional claims in published maps and institutional affiliations. 
(c) (i) Open Access This article is licensed under a Creative Commons Attribution 4.0 International cc) License, which permits use, sharing, adaptation, distribution and reproduction in any medium or format, as long as you give appropriate credit to the original author(s) and the source, provide a link to the Creative Commons licence, and indicate if changes were made. The images or other third party material in this article are included in the article's Creative Commons licence, unless indicated otherwise in a credit line to the material. If material is not included in the article's Creative Commons licence and your intended use is not permitted by statutory regulation or exceeds the permitted use, you will need to obtain permission directly from the copyright holder. To view a copy of this licence, visit http://creativecommons.org/licenses/by/4.0/.

(C) The Author(s) 2021 